\title{
Extension of Aquaponic Water Use for NFT Baby-Leaf Production: Mizuna and Rocket Salad
}

\author{
Carlo Nicoletto ${ }^{1, *(1)}$, Carmelo Maucieri ${ }^{1}$, Alex Mathis ${ }^{2}$, Zala Schmautz ${ }^{2}$ (D), Tamas Komives ${ }^{3,4}$, \\ Paolo Sambo ${ }^{1}$ (D) and Ranka Junge 2 (iD) \\ 1 Department of Agriculture, Food, Natural Resources, Animals and Environment-University of Padova, \\ Campus of Agripolis, 35122 Legnaro (PD), Italy; carmelo.maucieri@unipd.it (C.M.); \\ paolo.sambo@unipd.it (P.S.) \\ 2 Institute of Natural Resource Sciences, Campus Grüental, Zurich University of Applied Sciences, \\ 8400 Wädenswil, Switzerland; alex.mathis@zhaw.ch (A.M.); zala.schmautz@zhaw.ch (Z.S.); \\ ranka.junge@zhaw.ch (R.J.) \\ 3 Plant Protection Institute, Hungarian Academy of Sciences, Centre for Agricultural Research, \\ Herman Otto 15, 1022 Budapest, Hungary; komives.tamas@agrar.mta.hu \\ 4 Faculty of Agricultural Science, Esterhazy Karoly University, Matrai ut 36, 3200 Gyongyos, Hungary \\ * Correspondence: carlo.nicoletto@unipd.it; Tel.: +39-049-827-2826
}

Received: 16 April 2018; Accepted: 14 May 2018; Published: 17 May 2018

\begin{abstract}
Aquaponics is a recirculating technology that combines aquaculture with hydroponics. It allows nutrients from fish waste to feed plants and thus saves water and nutrients. However, there is a mismatch between the nutrients provided by the fish waste and plant needs. Because of this, some nutrients, notably N, tend to accumulate in the aquaponic water (APW or AP water). The aim of this study was to investigate how APW, which is depleted of P and K but still rich in N, could be further utilized. APW was used in a mesocosm and compared with APW from the same source that had been supplemented with macro-nutrients (complemented AP water or CAPW) and a hydroponic control (HC). Mizuna (M) and rocket salad (R) were used as short-cycle vegetable crops in a NFT system. The results revealed that the low production potential of APW was mainly caused by the lack of $\mathrm{P}$ and $\mathrm{K}$. If these were supplemented, the yields were comparable to those in the HC. $M$ yield in CAPW was significantly higher than that of $\mathrm{HC}$, probably due to biostimulant effects connected to the organic components in the water as a result of fish farming. Water type, cultivation density, and intercropping significantly influenced the qualitative characteristics of the crop in terms of antioxidant compounds and minerals. Nitrate content in vegetables was lower than European regulation limits. The extended use of APW is viable if the missing nutrients are supplemented; this could be a strategy to increase the efficiency of water and nitrogen use, while further reducing environmental impact.
\end{abstract}

Keywords: biomass yield; nutritional quality; sustainability; vegetables intercropping; secondary metabolites; nutrient film technique

\section{Introduction}

Aquaculture is perceived to have the greatest potential for meeting the growing demand for aquatic food [1]. It is estimated that a minimum of an additional 40 million tons of aquatic food will be required by 2030 to maintain current per capita consumption. Traditional, non-recirculating aquaculture systems require large amounts of high quality water and emit huge amounts of wastewater that is rich in nutrients. Aquaponics (AP), the combined culture of fish and plants in closed recirculating systems [2], is one of the solutions to both of these problems [3,4]. AP has received considerable 
attention due to its potential to sustain water quality, minimize water exchange, reduce the use of water, and increase the productivity by yielding fresh healthy fish, vegetables, fruits, and herbs [5-7].

In aquaponics, the cultivation of plants is performed in different soilless systems that use and recirculate the water from the fish farming $[4,8,9]$. In a closed loop aquaponics system, all of the water recirculates between the aquaculture and hydroponic parts of the system. In an open-loop (or uncoupled) system, only a portion of the aquaculture water is used for aquaponics and is not recycled back to the fish compartment [10]. The main challenge in closed loop aquaponics is to maintain optimal conditions for fish and plants, since the requirements of both compartments are different.

If the optimum ratio between daily feed input and plant growing area is maintained, the aquaculture effluent provides most of the nutrients required by the plants [11]. However, this ratio depends on many factors and changes over time. Even if there is a mismatch between the water composition requirements of the plants and the fish from the very beginning of cultivation [12], this will not become obvious if there are only a few plants or the cultivation periods are very short. Because there is a mismatch between the nutrients provided by the effluent from the fish compartment and the requirements of the plants, the system will limit plant growth over time (usually as a result of deficiencies in $\mathrm{P}$ and/or K) [13]. This causes the remaining $\mathrm{N}$, and other ions, to accumulate in the system water [12], increasing total salinity levels. In this case, it is necessary to either reduce the fish load, which is undesirable, or partially replace the system water. Another option for maintaining a suitable equilibrium in the system would be to introduce a desalination step [14], but this prospect has not yet been tested in practice. The option of removing and replacing some of the recirculation water entails discharging water with high levels of potentially valuable N. Information on further use of this water for growing vegetables is very limited and this could represent the missing opportunity that further increases the efficiency of water and nutrient use.

While different vegetable species, mainly lettuce, water spinach, basil, tomato, and chicory, have been investigated in AP $[4,5,15]$ very few studies have been carried out to evaluate microgreens and baby-leaf production. Consumption of microgreens and baby-leaf is increasing worldwide [16-18], and they can provide a substantial proportion of the recommended dietary allowance of a number of healthy compounds (ascorbic acid, thiamin, riboflavin, and a range of minerals) [19]. These products, which are characterized by a very short growth cycle might, therefore, be able to adapt very well to the use of water derived from AP systems. Furthermore, shortly after germination, the young plants can still use some of the nutrients provided in the seed and thus there is a delay before their growth becomes limited.

The aim of this study was to investigate the further utilization of AP system water that is depleted of $\mathrm{P}$ and $\mathrm{K}$, but still rich in $\mathrm{N}$. This system water (AP water or APW) was used in an AP mesocosm and compared with water from the same source that was supplemented with macro-nutrients (complemented AP water or CAPW), and a hydroponic control (HC). Mizuna (M) and rocket salad (R) were used as short-cycle vegetables crops in a Nutrient Film Technique (NFT) system.

\section{Materials and Methods}

\subsection{Experiment Set-Up}

Experiments were conducted in a foliar-tunnel greenhouse at the Zurich University of Applied Sciences (ZHAW) in 2017. Temperature and light intensity data during the two cultivation cycles are shown in Figure 1. Nine mesocosm systems consisting of one tank each $(275 \mathrm{~L})$ and 4 NFT channels for vegetable cultivation (Figure 2) were used for this experiment. 

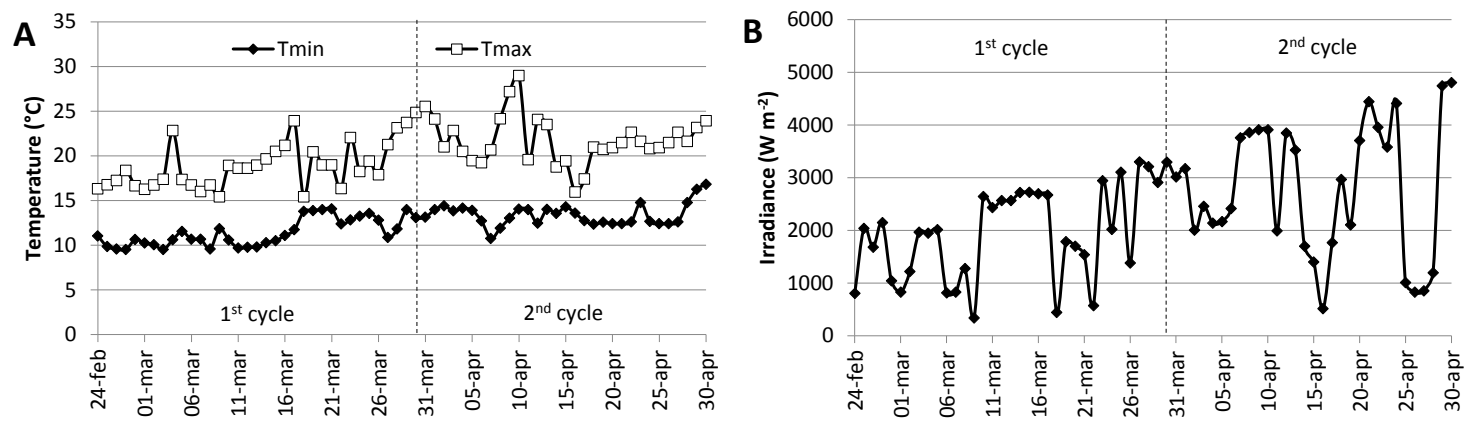

Figure 1. Meteorological conditions recorded during two growth cycles: temperature (A) and irradiance values (B) obtained from Zurich University of Applied Sciences (ZHAW) meteorological station.

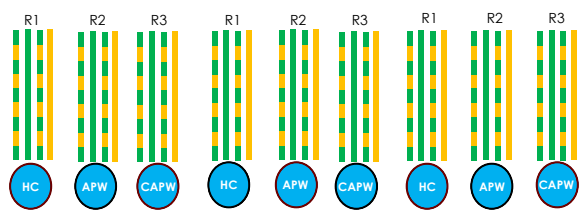

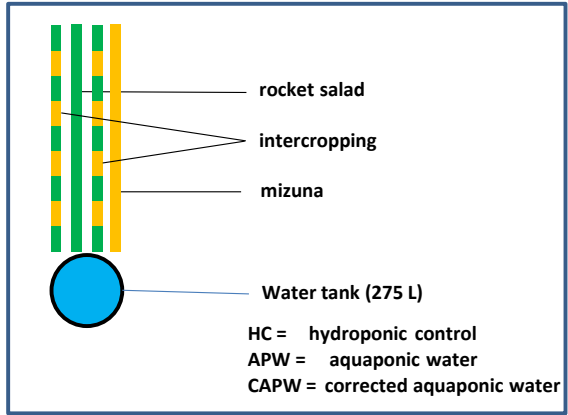

(a)

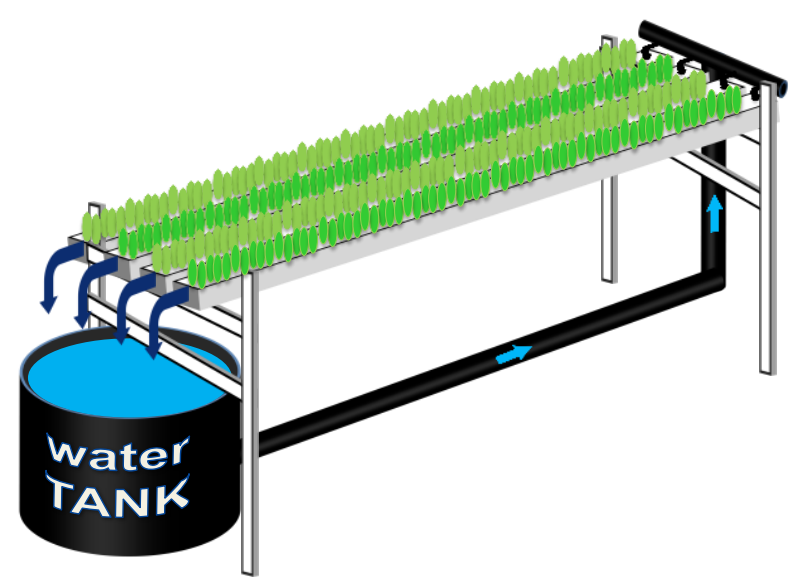

(b)

Figure 2. Overview of the experimental design (a) and a single cultivation mesocosms (b).

The water $\left(1.65 \mathrm{~m}^{3}\right)$ from an already existing recirculating AP system (150 pangasius fish with an average weight of $300 \mathrm{~g}$ each in a tank of $3 \mathrm{~m}^{3}$ and $7.6 \mathrm{~m}^{2}$ planted area with a complete AP water volume of $7 \mathrm{~m}^{3}$ ) was diverted to operate the mesocosm AP systems. The AP water (APW), which contained almost exclusively nitrate nitrogen, was compared with the following: the same water supplemented with P and K plus meso- and micro-nutrients (CAPW); and a hydroponic control characterized by the same content of nitric nitrogen present in fish water with the same nutrients added as the supplemented fish water (HC). The three nutrient solutions (APW, CAPW, and HC) were compared using a randomized complete block design with three replicates; the nutrient solutions characteristics are summarized in Table 1.

Table 1. Chemical composition of the nutrient solutions in the experiment (target values). CAPW: complemented aquaponic water; APW: aquaponic water; HC: hydroponic control; EC: electric conductivity.

\begin{tabular}{|c|c|c|c|c|c|c|c|c|c|c|}
\hline \multirow{2}{*}{$\begin{array}{l}\text { Nutrient } \\
\text { Solution }\end{array}$} & $\mathrm{N}-\mathrm{NH}_{4}$ & $\mathrm{~N}-\mathrm{NO}_{2}$ & $\mathrm{~N}-\mathrm{NO}_{3}$ & $\mathbf{K}$ & $\mathrm{P}_{-\mathrm{PO}_{4}}{ }^{3}$ & $\mathrm{Ca}$ & $\mathrm{S}-\mathrm{SO}_{4}{ }^{2-}$ & $\mathrm{Mg}$ & $\mathrm{pH}$ & EC \\
\hline & \multicolumn{9}{|c|}{$\left(\mathrm{mg} \mathrm{L}^{-1}\right)$} & $\left(\mu S \mathrm{~cm}^{-1}\right)$ \\
\hline $\mathrm{HC}$ & 0 & 0 & 65 & 120 & 25 & 66 & 23.4 & 20 & 7.87 & 1718 \\
\hline APW & 0.075 & 0.023 & 63.5 & 0.078 & 1.55 & 66 & 27.6 & 21 & 7.79 & 824 \\
\hline CAPW & 0.075 & 0.023 & 63.5 & 120 & 25 & 66 & 23.4 & 20 & 7.13 & 1680 \\
\hline
\end{tabular}


The nutrient solutions were prepared according to the Resh (2012) method for leafy vegetables and the composition was calculated using free HydroBuddy software [20]. The amount of nutrient supplementation needed to reach target values was obtained using Iron DTPA and Multi Micro Mix (Ökohum GmbH, Herrenhof, Switzerland), Krista SOP, and Krista MKP (Yara UK Limited, Grimsby, UK), potassium nitrate (Haifa Chemicals, Ltd., Haifa, Israel), and magnesium sulphates ( $\mathrm{K}+\mathrm{S}$ Kali $\mathrm{GmbH}$, Kassel, Germany). The three nutrient solutions allowed for the evaluation of the effect of nutrient supply in mineral form and/or organic form.

\subsection{Plant Material and Samplings}

Rocket salad (Eruca vesicaria: R) and mizuna (Brassica rapa L. spp. Nipposinica: M) were grown for two consecutive growth cycles (2 February-3 March 2017; 3 March-30 April 2017). In order to evaluate the suitability of these species for the aquaponics cultivation, different seed densities and intercropping of both plants were tested. The four NFT channels in each system were prepared as follows: high density sowing (3000 plants $\mathrm{m}^{-2}$ ) for rocket salad (RHD) and mizuna (MHD); high density mizuna and rocket salad intercropping (MIHD and RIHD); low density mizuna and rocket salad intercropping (MILD and RILD) resulting in a total of 1500 plants $\mathrm{m}^{-2}$ (Table 2) and obtaining six vegetable treatments.

Table 2. Vegetable treatments and their abbreviations.

\begin{tabular}{ccc}
\hline Vegetable Treatments & Plant Density & Abbreviation \\
\hline Mizuna high density & & MHD \\
Rocket salad high density & \multirow{2}{*}{$3000{\text { plants } \mathrm{m}^{-2}}^{\text {RHD }}$} \\
Intercropping high density & & MIHD \\
& & RIHD \\
\hline \multirow{2}{*}{ Intercropping low density } & \multirow{2}{*}{$1500{\text { plants } \mathrm{m}^{-2}}^{2}$} & MILD \\
& & RILD \\
\hline
\end{tabular}

The seeds were sown using a self-constructed sowing device on a synthetic carpet $(80 \%$ viscose and $20 \%$ polyester-Growfelt, UK) placed in the bottom of the NFT channels and kept moist until germination. After this, the automatic irrigation system was activated for three daily periods of one hour each $(9.00-10.00 ; 12.00-13.00 ; 16.00-17.00)$. During the crop cycle, the evapotranspired water was replaced every second day with fresh water and the amount of water added was recorded. Non-destructive plant measurements such as plant height and chlorophyll content values (Chlorophyll meter SPAD-502 Konica Minolta) were performed three times a week. At the end of the baby-leaf growth cycle (plant height equal to $100-120 \mathrm{~mm}$ ), the total yield and dry matter $\left(65{ }^{\circ} \mathrm{C}\right)$ were determined. In addition, plant samples were taken in order to perform qualitative analyses in triplicate at the laboratories of the University of Padua (Italy).

\subsection{Water Quality Monitoring}

The nutrient solution was monitored three times a week by measuring $\mathrm{pH}$ and electric conductivity (EC) with a portable multi-parameter meter (HQ40d Portable Multi-Parameter Meter, Hach Lange $\mathrm{GmbH}$, Düsseldorf, Germany). Three times a week, the levels of nitrate nitrogen $\left(\mathrm{N}^{-\mathrm{NO}_{3}}{ }^{-}\right)$ were determined photometrically (cuvette test LTK339, Hach Lange GmbH, Germany). Samples were taken three times a week during the entire experiment for quantitative determination of $\mathrm{Na}^{+}, \mathrm{Mg}^{2+}$, $\mathrm{K}^{+}, \mathrm{Ca}^{2+}, \mathrm{Cl}^{-}, \mathrm{NO}_{3}{ }^{-}, \mathrm{PO}_{4}{ }^{3-}$, and $\mathrm{SO}_{4}{ }^{2-}$ using ion chromatography (930 Compact IC flex).

\subsection{Extraction of Phenols for Analysis}

Freeze-dried samples of baby-leaf salads $(0.2 \mathrm{~g})$ were homogenized in methanol $(20 \mathrm{~mL})$ using an Ultra Turrax T25 at 13.500 rpm until a uniform consistency was achieved. Samples were filtered (filter 
paper, 589 Schleicher) and appropriate aliquots of the extracts were analyzed using the Folin-Ciocalteu (FC) assay for total phenol (TP) content, and ferric reducing antioxidant power (FRAP) assay was used for measuring total antioxidant activity. For each sample, extractions and analyses were performed in triplicate.

\subsection{Determining Total Phenols Using the Folin-Ciocalteu Assay}

The TP content was determined using the FC assay with gallic acid as a calibration standard in a Shimadzu UV-1800 spectrophotometer (Shimadzu Scientific Instruments Inc., Columbia, MD, USA). The FC assay was carried out by pipetting $200 \mu \mathrm{L}$ of extract into a $10 \mathrm{~mL}$ polypropylene tube. This was followed by the addition of $1 \mathrm{~mL}$ of FC reagent. The mixture was vortexed for $30 \mathrm{~s}$, and then $800 \mu \mathrm{L}$ of filtered $20 \%$ sodium carbonate solution was added $1 \mathrm{~min}$ later. After a further $8 \mathrm{~min}$, the FC reagent was added. This was recorded as time zero; sodium carbonate was then added and the mixture was vortexed for $30 \mathrm{~s}$. After $2 \mathrm{~h}$ at room temperature, the absorbance of the colored reaction product was measured at $765 \mathrm{~nm}$. The content of TP in the extracts was calculated from a standard calibration curve, calculated for different concentrations of gallic acid, ranging from 0 to $600 \mu \mathrm{gL}^{-1}$ (correlation coefficient: $R^{2}: 0.9982$ ). The results were expressed as $\mathrm{mg}$ of gallic acid equivalent per $\mathrm{kg}$ $\left(\mathrm{mg} \mathrm{GAE} \mathrm{kg}{ }^{-1}\right)$ of dry matter [21].

\subsection{Determining Total Antioxidant Activity Using Ferric Reducing Antioxidant Power}

The Ferric Reducing Antioxidant Power (FRAP) reagent was prepared freshly, so that it contained $1 \mathrm{mM}$ 2,4,6-tripyridyl-2-triazine and $2 \mathrm{mM}$ ferric chloride in $0.25 \mathrm{M}$ sodium acetate at $\mathrm{pH} 3.6$ [22]. A $100 \mu \mathrm{L}$ aliquot of the methanol extract, prepared as described above, was added to $1900 \mu \mathrm{L}$ of FRAP reagent and thoroughly mixed. After leaving the mixture at $20^{\circ} \mathrm{C}$ for $4 \mathrm{~min}$, the absorbance at $593 \mathrm{~nm}$ was determined. Calibration was made against a standard curve $\left(0-1200 \mu \mathrm{g} \mathrm{mL}{ }^{-1}\right.$ ferrous ion) produced by the addition of freshly prepared ammonium ferrous sulfate. FRAP values were calculated in triplicate as $\mathrm{mg} \mathrm{mL}^{-1}$ ferrous ion (ferric reducing power) and are presented as $\mathrm{mg}$ of $\mathrm{Fe}^{2+} \mathrm{E}$ (ferrous ion equivalent) $\mathrm{kg}^{-1} \mathrm{dw}$.

\subsection{Quantitative Determination of Anions and Cations Using Ion Chromatography (IC)}

IC was performed using an ICS-900 ion chromatography system (Dionex Corp., Milan, Italy) equipped with a dual piston pump, a model AS-DV autosampler, an isocratic column at room temperature, a DS5 conductivity detector, an AMMS 300 anion suppressor (4 mm), and a CMMS 300 cation suppressor $(4 \mathrm{~mm})$. Chromeleon 6.5 Chromatography Management Software (Dionex Corp., Milan, Italy) was used to control the system and process the data. A Dionex Ion-Pac AS23 (Dionex Corp., Milan, Italy) analytical column $(4 \mathrm{~mm} \times 250 \mathrm{~mm})$ and a guard column $(4 \mathrm{~mm} \times 50 \mathrm{~mm})$ were used for anion separation, whereas a Dionex IonPac CS12A 23 (Dionex Corp., Milan, Italy) analytical column $(4 \mathrm{~mm} \times 250 \mathrm{~mm})$ and a guard column $(4 \mathrm{~mm} \times 50 \mathrm{~mm})$ were used for cation separations. The eluent consisted of $4.5 \mathrm{mM}$ sodium carbonate and $0.8 \mathrm{mM}$ sodium bicarbonate at a flow rate of

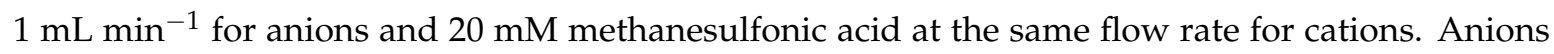
and cations were quantified after calibration. Different concentrations of Dionex solutions containing seven anions and five cations were used as standards, and the calibration curves were generated for concentrations ranging from $0.4 \mathrm{mg} \mathrm{L}^{-1}$ to $20 \mathrm{mg} \mathrm{L}^{-1}$ (anions) and from $0.5 \mathrm{mg} \mathrm{L}^{-1}$ to $50 \mathrm{mg} \mathrm{L}^{-1}$ (cations). Cations and anions (UNI EN12014-2) were quantified.

\subsection{Statistical Analysis}

The data were analyzed using analysis of variance (ANOVA) and in the case of a significant F-value, the means were compared using Tukey's Honest Significant Difference (HSD) test. 


\section{Results}

From a preliminary ANOVA statistical analysis, it was established that there were no significant differences between the two crop cycles that were carried out in each of the tested systems in terms of almost all of the evaluated parameters (Table 3). The pattern for each examined trait was not affected by growth cycle, therefore, it was considered appropriate to report data from both crop cycles to highlight the effect of the crop cycle on the absolute values for each parameter and not on the individual patterns.

Table 3. Statistical analysis (ANOVA) overview of the two growth cycles, comparing water and vegetables traits.

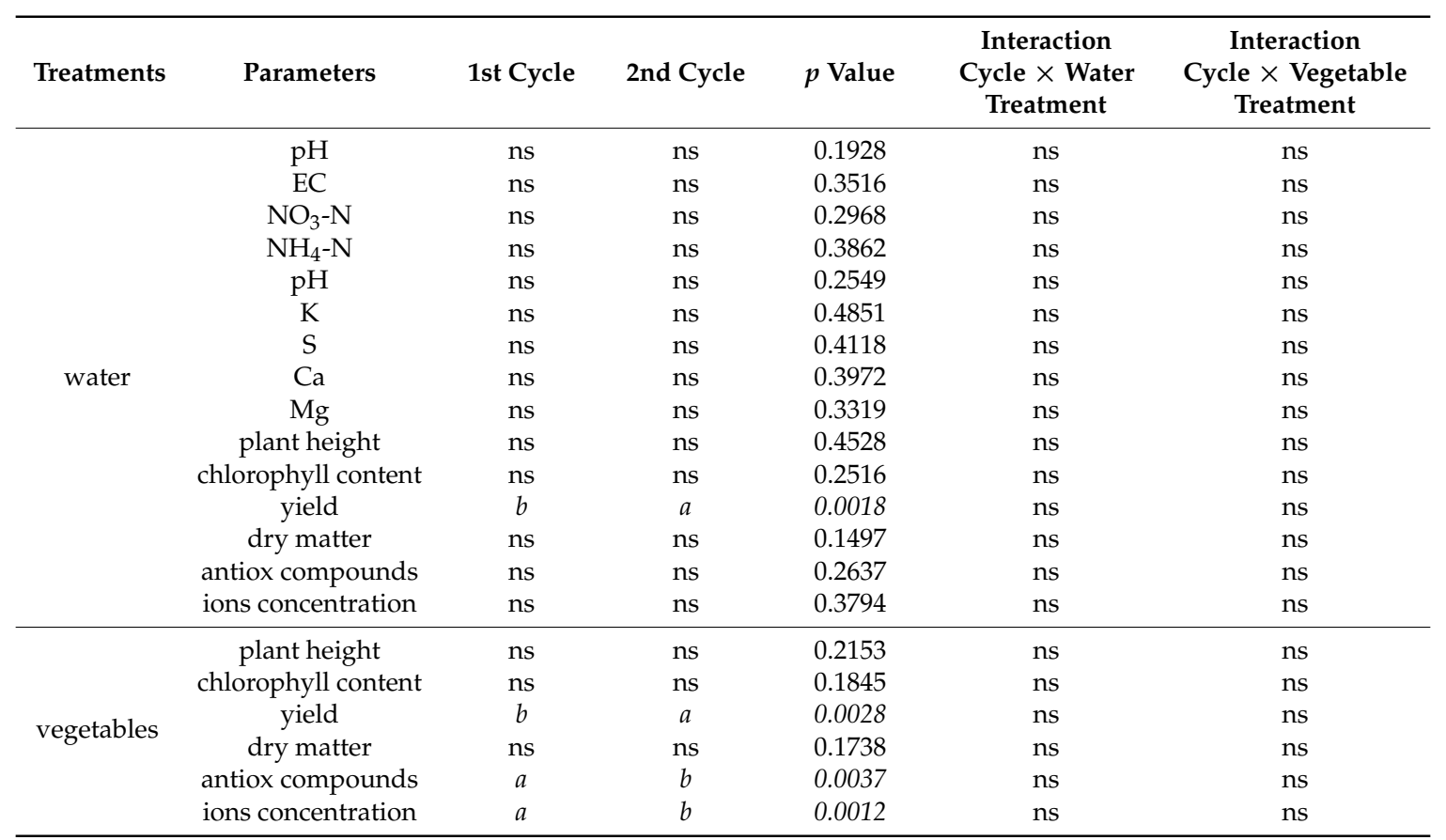

Values with different letters are significantly different with $p<0.05$ based on a Tukey Honest Significant Difference (HSD) test. ns: not significant.

\subsection{Nutrient Solutions}

Water consumption during both of the crop cycles was higher for HC and CAPW than that of APW. In the HC and CAPW systems, 213 and $218 \mathrm{~L}$ water, respectively, had to be replaced during the first cycle, while in the APW system, only $182 \mathrm{~L}$ were replaced; the same pattern was recorded during the second cycle, albeit with generally lower values: 182, 177, and $161 \mathrm{~L}$, respectively, for the $\mathrm{HC}, \mathrm{CAPW}$, and APW systems.

The $\mathrm{pH}$ values during both cycles increased from near neutral values to basic ( 9.0) in the final stages of the experiment (Figure 3). There were statistically significant differences between the nutrient solutions, especially in the first phase of the crop cycle. The breakdown threshold was recorded 24 days after seeding (DAS), after which there were no differences in $\mathrm{pH}$ values. The $\mathrm{pH}$ was consistently the highest in the HC system. The levels of electrical conductivity (EC) decreased in the HC and CAPW systems, in contrast to the APW system, where the EC remained fairly stable during both crop cycles (Figure 3). The APW system had the lowest EC values, close to $800 \mu \mathrm{S} \mathrm{cm}^{-1}$ in both crop cycles. The HC and CAPW system values exhibited an average EC decrease equal to $22 \%$ and $25.5 \%$, respectively, in the 1st and 2nd cycles. 
1 CYCLE
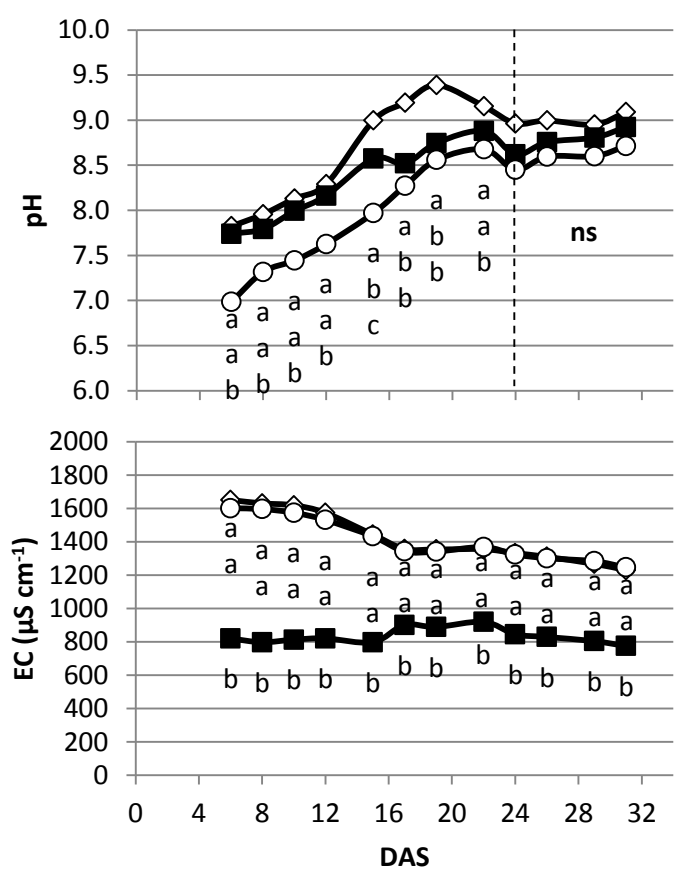

2 CYCLE
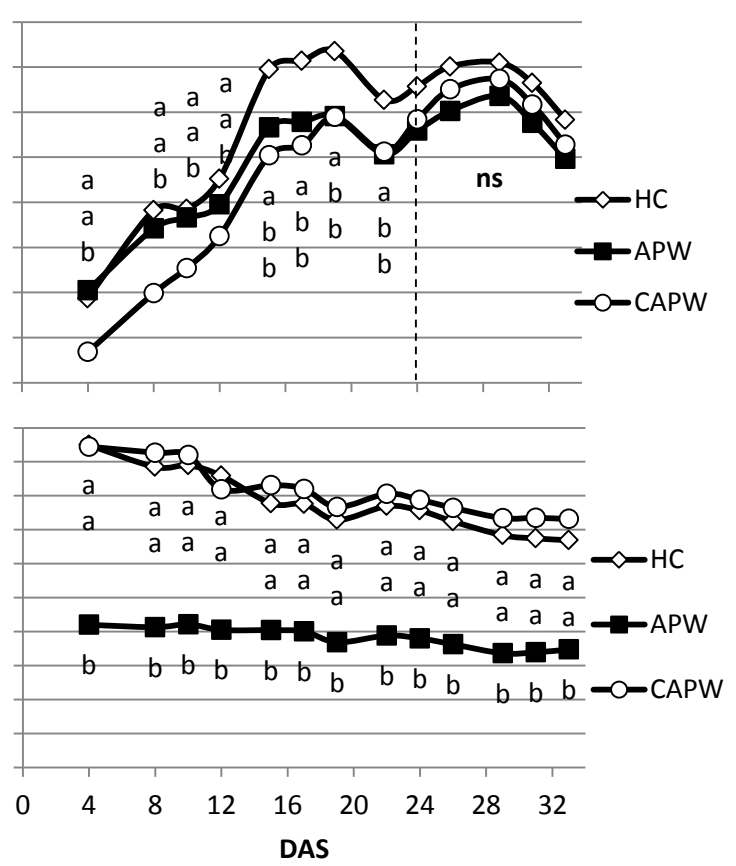

Figure 3. Effect of water treatment on $\mathrm{pH}$ and electric conductivity (EC) in both growth cycles. Values with different letters on the same day after sowing (DAS) are significantly different with $p<0.05$, based on Tukey HSD Test. HC: hydroponic control; APW: aquaponic water; CAPW: complemented aquaponic water.

The concentrations of macronutrients changed during the crop cycle, and the data obtained reveal well defined patterns (Figure 4). In the initial phase of the crop cycle, nitrate-nitrogen concentrations were high: $67.8 \mathrm{mg} \mathrm{L}^{-1}$ and $100.1 \mathrm{mg} \mathrm{L}^{-1}$ for the 1 st and 2nd cycles, respectively, whereas ammonium-nitrogen concentrations were low, $2.5 \mathrm{mg} \mathrm{L}^{-1}$ and $0.56 \mathrm{mg} \mathrm{L}^{-1}$ for the 1st and 2nd cycles, respectively. $\mathrm{NO}_{3}-\mathrm{N}$ values gradually decreased during the entire crop cycle, whereas $\mathrm{NH}_{4}-\mathrm{N}$ fluctuated at a low level, especially in the second half of the first crop cycle. The different nutrient solutions differed statistically after 18 and 15 DAS, respectively, in the 1st and 2nd cycles for $\mathrm{NO}_{3}-\mathrm{N}$. The APW system had the highest $\mathrm{NO}_{3}-\mathrm{N}$ concentrations. The ammonium-nitrogen values were predominantly different in the first phase of the crop cycle, with a breakdown threshold identified after 20 and 15 DAS, respectively, for the 1st and 2nd cycles. Phosphorous concentration was extremely low in the APW nutrient solution, with values lower than $3.26 \mathrm{mg} \mathrm{L}^{-1}$ (Figure 4). It was higher in the HC and CAPW systems, but only in the first phase of both crop cycles (until 22 DAS and 14 DAS for the 1st and 2nd cycles, respectively), then, the values dropped and were comparable to those of the APW system. Finally, K concentration was found to be more or less constant throughout both crop cycles (Figure 4). A slight decrease in K concentration was recorded in the HC and CAPW systems in the final phase of cultivation, and it was very low in the APW system, with values lower than $20 \mathrm{mg} \mathrm{L}^{-1}, 83.3 \%$ lower than target values. 
1 CYCLE
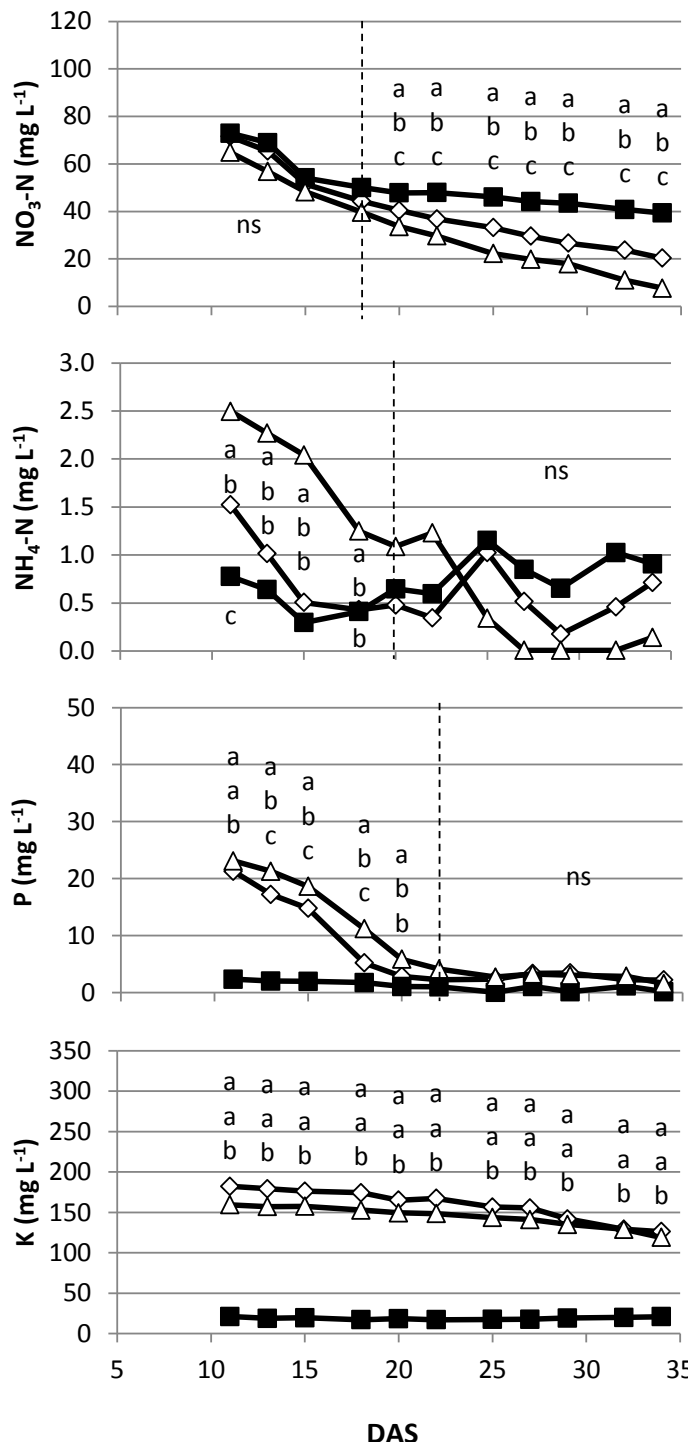

2 CYCLE
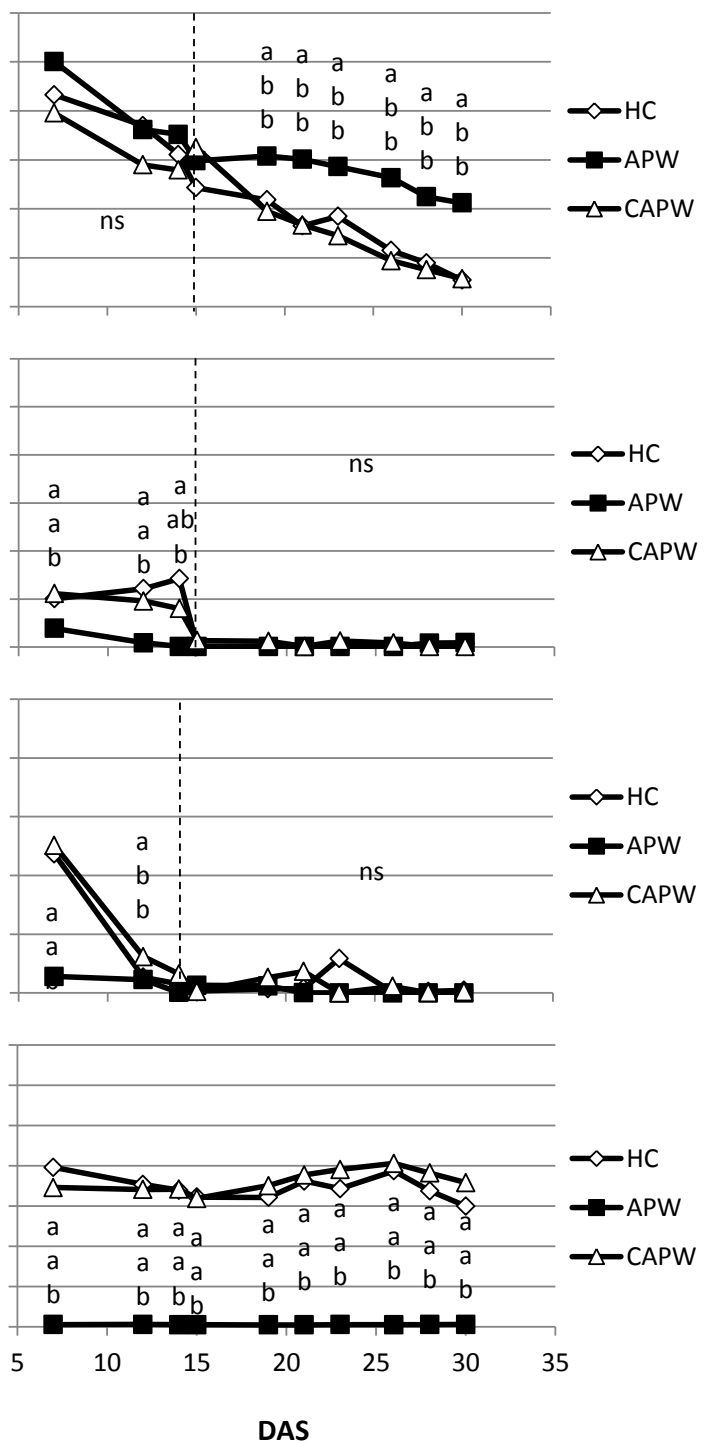

Figure 4. Effect of water treatment on nitrogen, phosphorus, and potassium concentrations during both growth cycles. Different letters on the same DAS indicate significant differences with $p<0.05$, based on Tukey HSD Test. HC: hydroponic control; APW: aquaponic water; CAPW: complemented fish water.

The concentrations of sulphur (S), calcium (Ca), and magnesium $(\mathrm{Mg})$ were influenced by the water treatment and also differed between the crop cycles (Figure 5). In general, the concentration of $\mathrm{S}$, $\mathrm{Ca}$, and $\mathrm{Mg}$ fluctuated less in the first cycle than in the second one. The $\mathrm{S}$ content ranged from 10.3 to $59.7 \mathrm{mg} \mathrm{L}^{-1}$ in the first cycle, whereas in the second one, especially for CAPW, the values were higher and ranged between 25.4 and $109.8 \mathrm{mg} \mathrm{L}^{-1}$. The Ca content, comparable in both crop cycles, was higher in CAPW, whereas HC differed from APW only during the first part of the crop cycle. Finally, the magnesium content was higher in $\mathrm{HC}$ and was statistically different from the other treatments during the middle phases of the first crop cycle; in the second cycle, APW never differentiated from CAPW. 
1 CYCLE
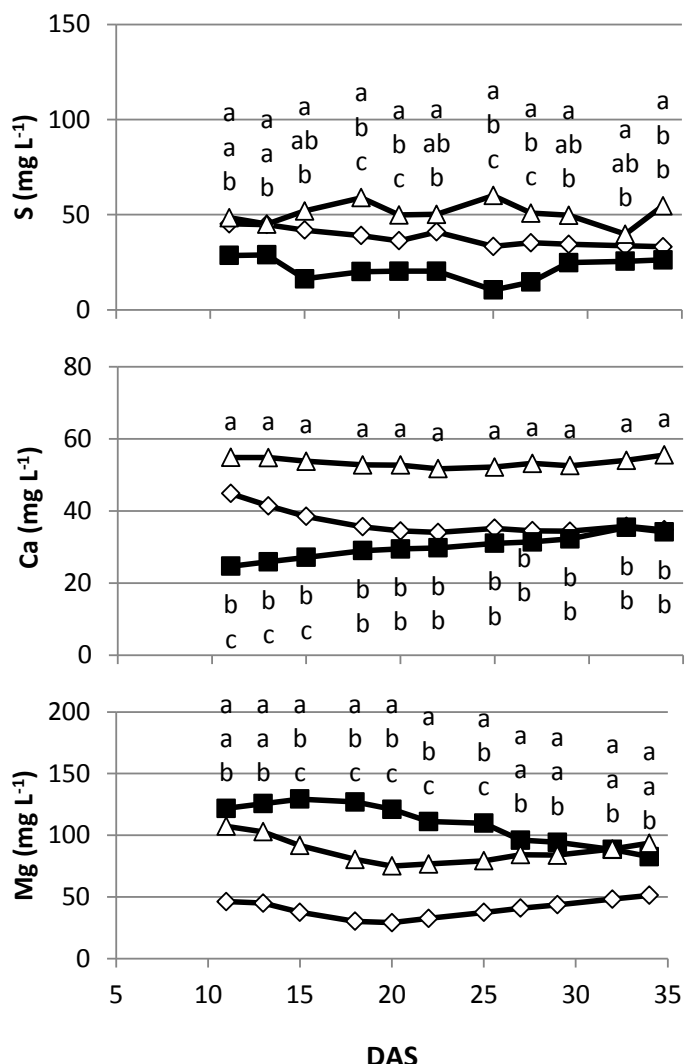

2 CYCLE
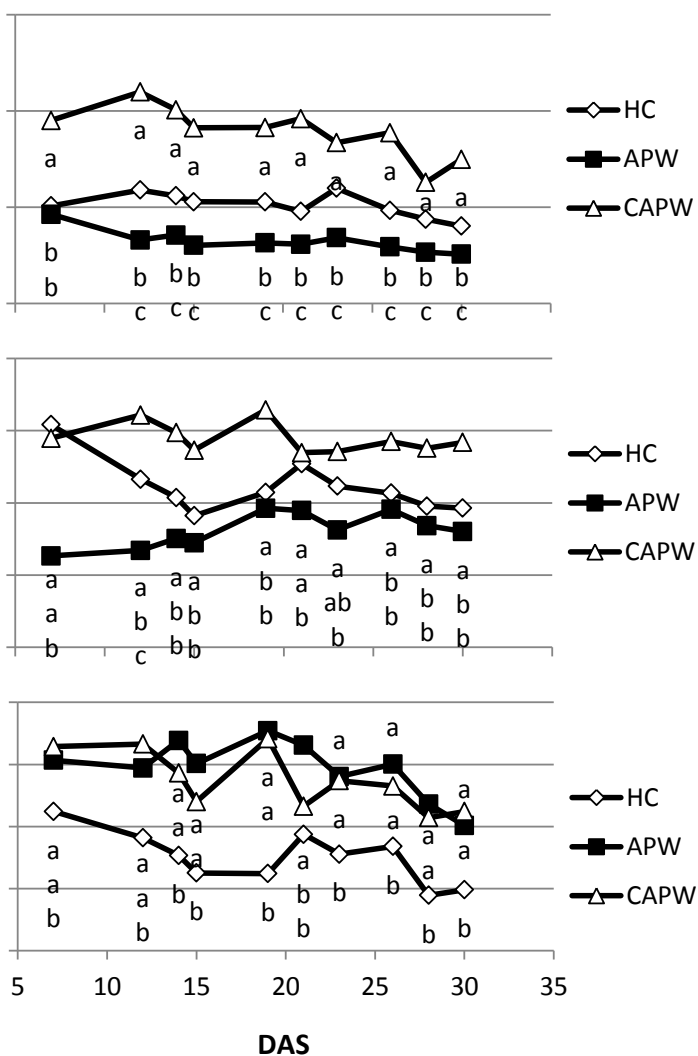

Figure 5. Effect of water treatment on sulphur, calcium, and magnesium concentrations during the growth cycles. Different letters on the same DAS indicate significant differences, with $p<0.05$, based on Tukey HSD Test. HC: hydroponic control; APW: aquaponic water; CAPW: complemented aquaponic water.

\subsection{Vegetables Species}

Mizuna (M) and rocket salad (R) are widely produced ready-to-eat baby leaves. When cultivated in soilless production systems, either in monocultures or intercropped, they differ in terms of several productive and qualitative aspects. Mizuna (M) plants were generally higher (Figure 6) and reached heights close to $12 \mathrm{~cm}$ in the final phase of both crop cycles; rocket salads reached heights of between 5.5 and $8.0 \mathrm{~cm}$ in the first crop cycle, but did not exceed $6 \mathrm{~cm}$ in the second cycle. Height was influenced by crop density and intercropping in both cultivation cycles; however, plant density was the most significant parameter in determining the plant height. The type of nutrient solution also affected the plant height, which was higher in the HC and CAPW systems than the APW system. A slight deviation was observed between the two cultivation cycles, represented by the presence of significant differences in plant height in the 2nd cycle between the HC and CAPW systems after 18 DAS, which were not recorded in the 1st cycle. In the APW system, the height of the rocket salads did not exceed $3 \mathrm{~cm}$.

Intercropping of $\mathrm{M}$ and $\mathrm{R}$ did not markedly affect the chlorophyll content (Figure 7). However, the effect of the nutritional solution was significant. Plants in the HC and CAPW systems always exhibited higher values than those grown in APW. 

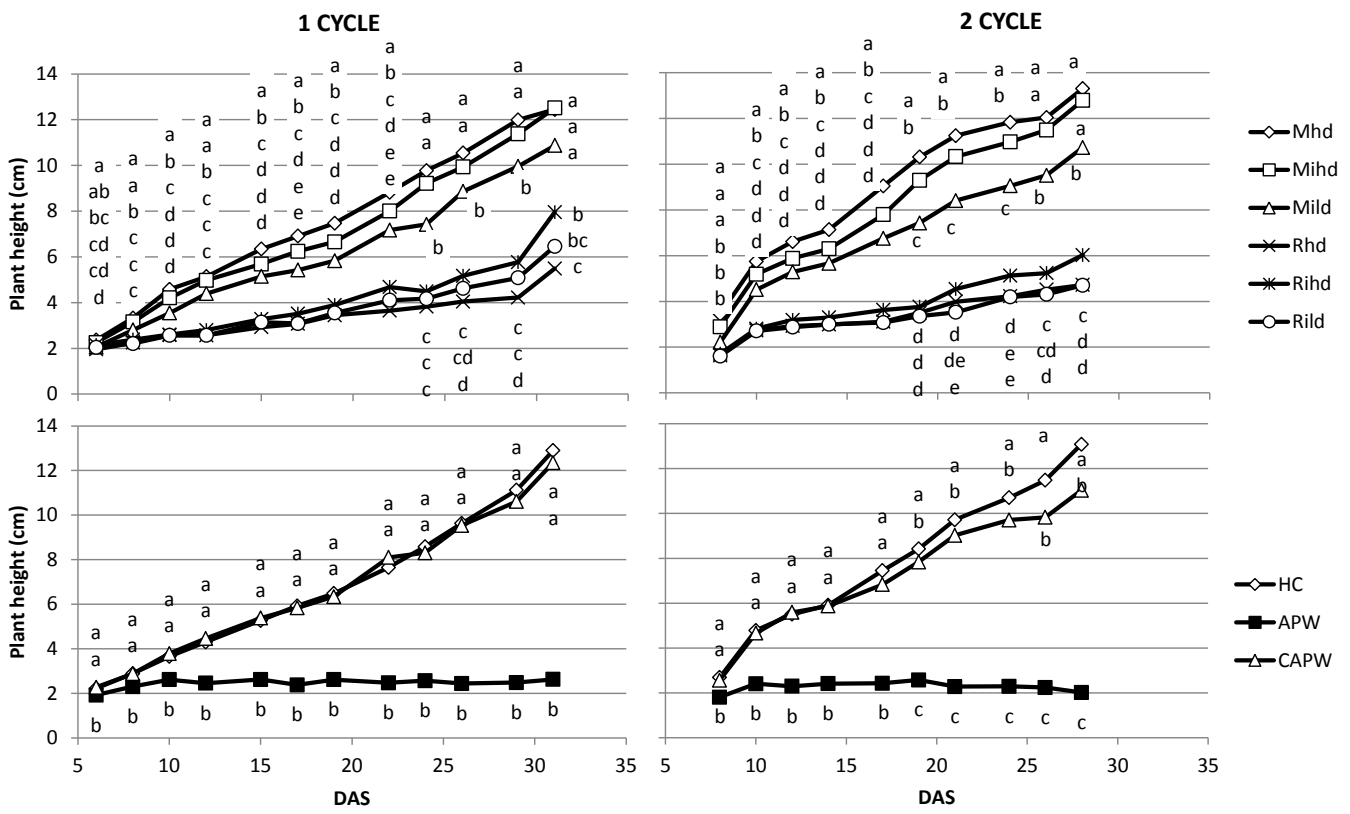

Figure 6. Effect of vegetable species and water treatment on plant height over two growth cycles. MHD: mizuna high density; MIHD: mizuna intercropped high density; MILD: Mizuna intercropped low density; RHD: rocket salad high density; RIHD: rocket salad intercropped high density; RILD: rocket salad low density; HC: hydroponic control; APW: aquaponic water; CAPW: complemented aquaponic water. Different letters on the same DAS indicate significant differences, with $p<0.05$, based on Tukey HSD Test.
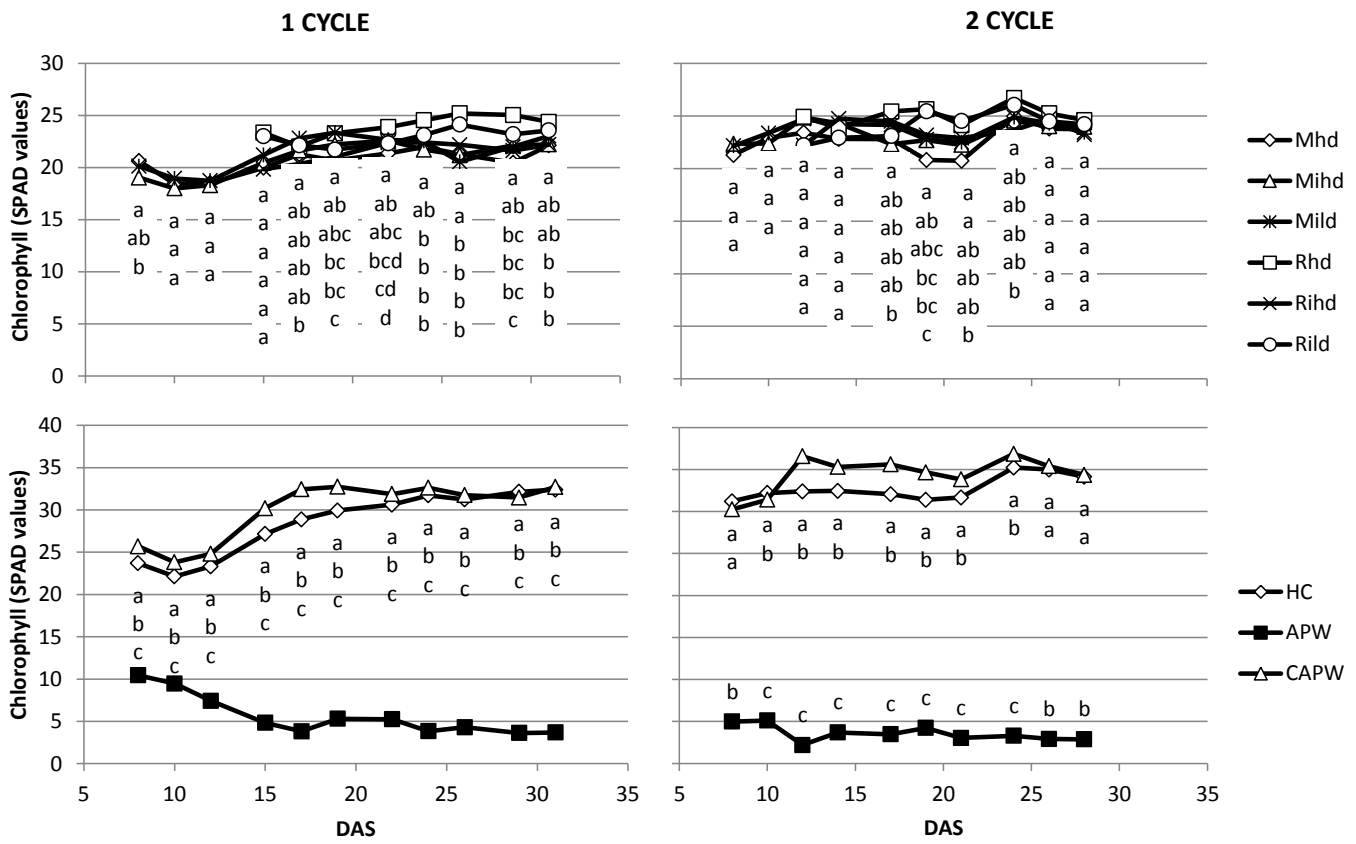

Figure 7. Effect of vegetable species and water treatment on chlorophyll content values over two growth cycles. MHD: mizuna high density; MIHD: mizuna intercropped high density; MILD: Mizuna intercropped low density; RHD: rocket salad high density; RIHD: rocket salad intercropped high density; RILD: rocket salad low density; HC: hydroponic control; APW: aquaponic water; CAPW: complemented aquaponic water. Different letters on the same DAS indicate significant differences, with $p<0.05$, based on Tukey HSD Test. 
The production potential of the two vegetables differed, with $\mathrm{M}$ delivering consistently higher yields than R (Figure 8). The nutritive solution also strongly influenced crop yield, with higher yields being delivered by the CAPW system; the latter water treatment exerted a significant difference with HC only in the second crop cycle (Figure 8 ). The APW system was characterized by yields lower than $0.5 \mathrm{~kg} \mathrm{~m}^{-2}$.
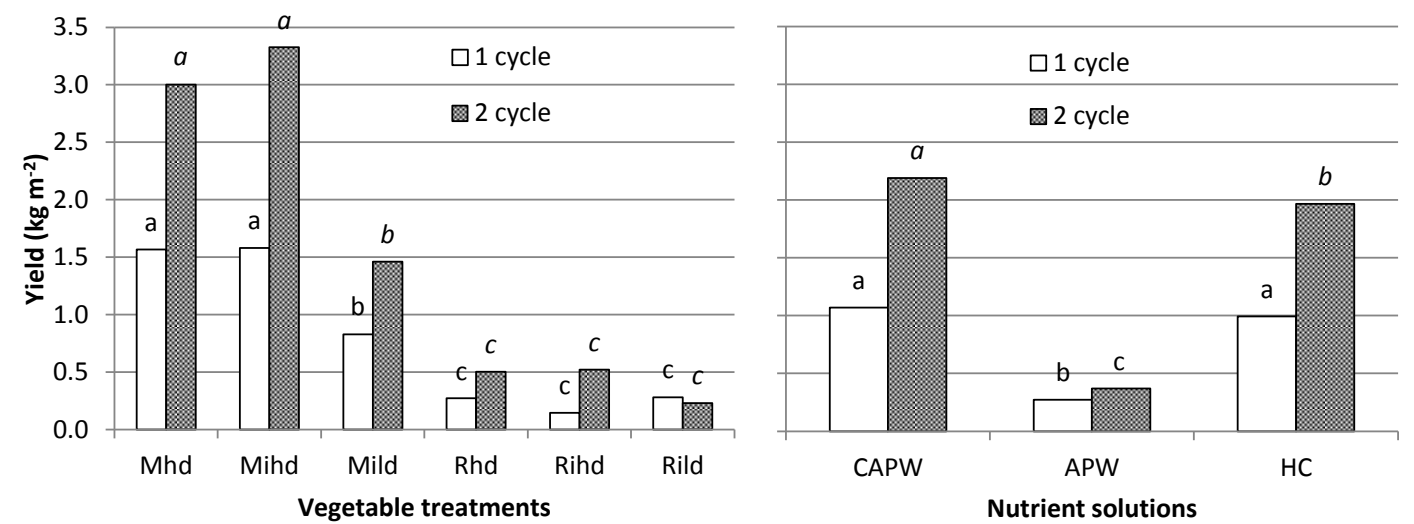

Figure 8. Effect of vegetable treatments and nutrient solutions on yields from two growth cycles. MHD: mizuna high density; MIHD: mizuna intercropped high density; MILD: Mizuna intercropped low density; RHD: rocket salad high density; RIHD: rocket salad intercropped high density; RILD: rocket salad low density; HC: hydroponic control; APW: aquaponic water; CAPW: complemented aquaponic water. Different letters on the same DAS indicate significant differences, with $p<0.05$, based on Tukey HSD Test.

The effect of the vegetable treatment was significant (Figure 9) for both growth cycles, highlighting the different potential production capacities of the species. In the first crop cycle, the CAPW system $M$ yield was always higher than that of the HC system. However, the R yield from the HC system proved to be significantly higher than that of the CAPW system. In the second crop cycle, a similar trend was observed, although the MILD values from the HC system were slightly higher than those of the CAPW system.

1 CYCLE

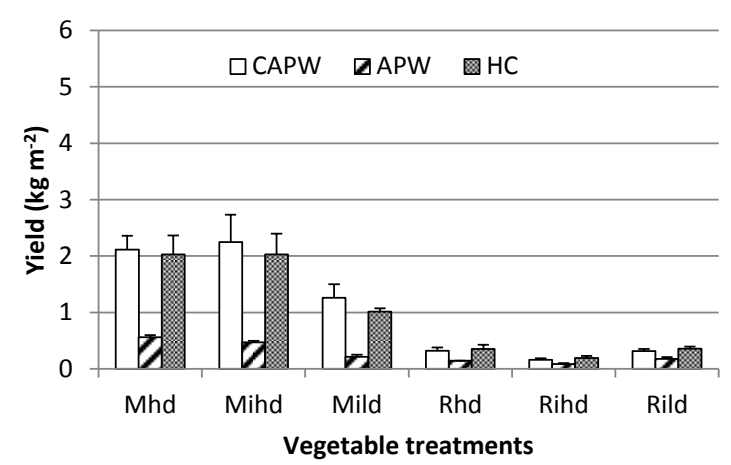

2 CYCLE

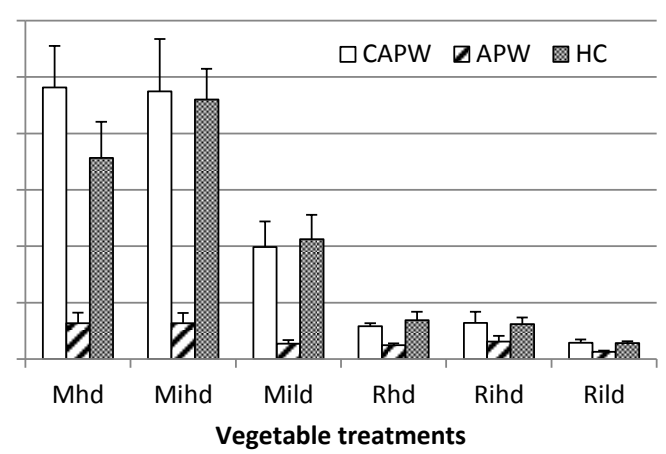

Figure 9. Effect of vegetable treatments and nutrient solutions on yields from two growth cycles. MHD: mizuna high density; MIHD: mizuna intercropped high density; MILD: Mizuna intercropped low density; RHD: rocket salad high density; RIHD: rocket salad intercropped high density; RILD: rocket salad low density; HC: hydroponic control; APW: aquaponic water; CAPW: complemented aquaponic water.

The dry matter content of the leaves was affected by the vegetable species, the crop density, and the nutrient solution (Figure 10), with R generally having a higher dry matter content than M. 
Furthermore, the higher $\mathrm{R}$ plant density without intercropping resulted in the highest dry matter content $(>16 \%)$. The highest dry matter percentage in both cultivation cycles was found in plants grown in the CAPW system, with values higher than $14 \%$.
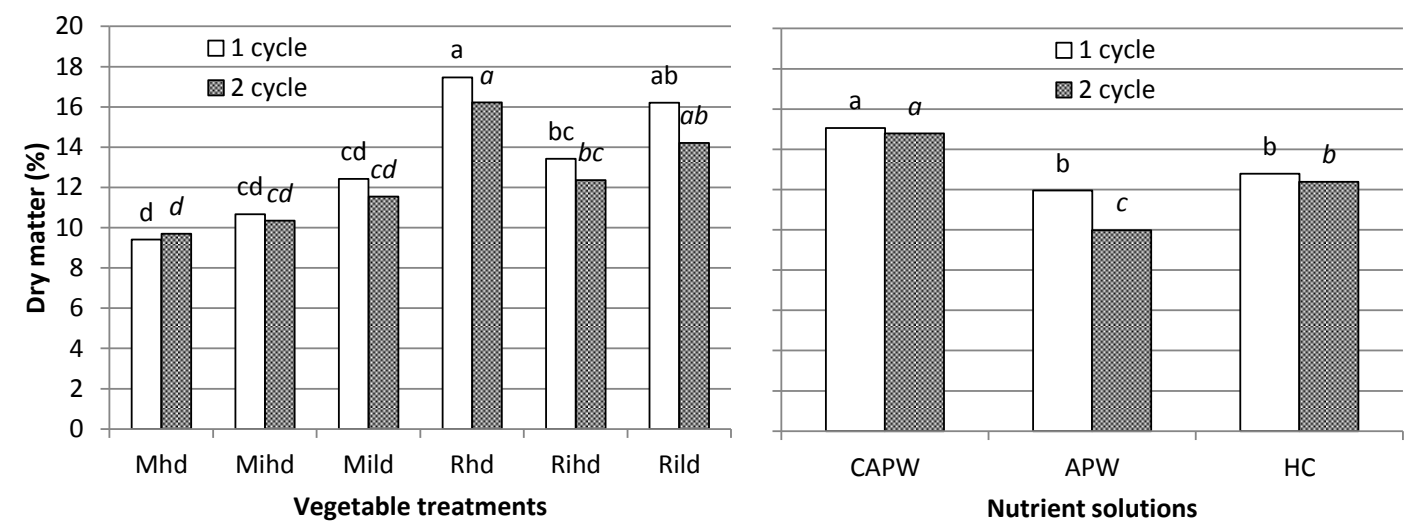

Figure 10. Effect of vegetable treatments and nutrient solutions on dry matter percentage for two growth cycles. MHD: mizuna high density; MIHD: mizuna intercropped high density; MILD: Mizuna intercropped low density; RHD: rocket salad high density; RIHD: rocket salad intercropped high density; RILD: rocket salad low density; HC: hydroponic control; APW: aquaponic water; CAPW: complemented aquaponic water. Different letters on the same DAS indicate significant differences, with $p<0.05$, based on Tukey HSD Test.

The levels of total antioxidant capacity (AOC), total polyphenols (TP), and vitamin C were generally higher in the first cycle than in the second one. The AOC values were significantly higher in plants grown in the APW and HC systems than of those in the CAPW systems for both cultivation cycles (Table 4). A similar trend was observed for the TP values, while the vitamin C concentration was highest in the plants grown in the APW system. In terms of the vegetable treatments, the AOC values were higher in RHD than MHD in the first cycle. Furthermore, the intercropped treatments also delivered different results: in the case of $\mathrm{R}$, intercropping reduced AOC, whereas the opposite was observed for M. Lower TP contents were recorded in both MHD cultivation cycles, whereas higher TP contents were observed in the $\mathrm{R}$ treatments, with no significant effects due to crop density. Finally, the vitamin C content was significantly higher in the R treatments, especially for RHD and RIHD. The concentration of vitamin $\mathrm{C}$ in $\mathrm{M}$ was stable in all of the treatments and not significantly influenced by crop density.

The mineral composition of the cultivated species was comparable in both growth cycles (Tables 5 and 6). Generally, the concentration of ions detected in the second cycle was slightly higher than those of the first cycle, with the exception of the $\mathrm{NO}_{3}{ }^{-}$content. This parameter was on average lower than $8.7 \%$ and $25.9 \%$, respectively, for nutrient solutions and vegetable treatments. Nutrient solutions heavily influenced the ion concentration in the plant, especially in the case of the APW system. The APW treatment resulted in a significant increase in the remaining ions, with the exception of $\mathrm{PO}_{4}{ }^{3-}$ and $\mathrm{K}^{+}$. For the APW system, it was possible to observe an average Ca difference in the first and second cycles of $70.3 \%$ and $73.3 \%$ compared to the HC and CAPW systems, respectively. $\mathrm{NH}_{4}{ }^{+}$ absorption was also significantly higher in the first and second cycles in the APW system by $82.1 \%$ and $83.7 \%$ compared to the $\mathrm{HC}$ and CAPW system averages respectively. $\mathrm{Na}^{+}$and $\mathrm{Cl}^{-}$were also readily absorbed in the APW system plants. The content of $\mathrm{PO}_{4}{ }^{3-}$ and $\mathrm{K}^{+}$was statistically higher in the HC and CAPW systems compared to that of APW. In terms of the vegetable treatments, the highest concentration of almost all the nutrients was observed in MHD. In the first cycle, high $\mathrm{Cl}^{-}$and $\mathrm{NO}_{2}{ }^{-}$ contents were recorded in RIHD and a high $\mathrm{SO}_{4}{ }^{2-}$ content was observed in MIHD. In the second cycle, RIHD resulted in a high $\mathrm{PO}_{4}{ }^{3-}$ content (9554 $\mathrm{mg} \mathrm{kg}^{-1} \mathrm{dw}$ ); MIHD and MILD were characterized by a high $\mathrm{NH}_{4}{ }^{+}$content above $1200 \mathrm{mg} \mathrm{kg}^{-1} \mathrm{dw}$. 
Table 4. Effect of water and vegetable treatments on antioxidant components concentration.

\begin{tabular}{|c|c|c|c|c|c|c|}
\hline & \multicolumn{2}{|c|}{$\begin{array}{l}\text { Antioxidant Capacity } \\
\left(\mathrm{g} \mathrm{Fe}^{2+} \mathrm{E} \mathrm{kg}^{-1} \mathrm{dw}\right)\end{array}$} & \multicolumn{2}{|c|}{$\begin{array}{c}\text { Total Phenols } \\
\left(\mathrm{g} \mathrm{GAE} \mathrm{kg}^{-1} \mathrm{dw}\right)\end{array}$} & \multicolumn{2}{|l|}{$\begin{array}{c}\text { Vitamin } C \\
\left(g^{-1} g^{-1} \mathrm{dw}\right)\end{array}$} \\
\hline & 1 Cycle & 2 Cycle & 1 Cycle & 2 Cycle & 1 Cycle & 2 Cycle \\
\hline \multicolumn{7}{|c|}{ Nutrient solutions } \\
\hline $\mathrm{HC}$ & $50.4 \pm 1.3 \mathrm{a}$ & $45.2 \pm 4.7 \mathrm{a}$ & $5.12 \pm 0.98 \mathrm{a}$ & $4.90 \pm 0.48 \mathrm{a}$ & $3.31 \pm 0.12 b$ & $3.13 \pm 0.14 \mathrm{k}$ \\
\hline APW & $49.6 \pm 4.6 \mathrm{a}$ & $46.2 \pm 2.9 \mathrm{a}$ & $5.93 \pm 0.76 \mathrm{a}$ & $5.55 \pm 0.57 \mathrm{a}$ & $4.15 \pm 0.18 \mathrm{a}$ & $3.84 \pm 0.16$ \\
\hline CAPW & $39.0 \pm 5.4 \mathrm{~b}$ & $35.6 \pm 3.3 \mathrm{~b}$ & $4.34 \pm 0.59 \mathrm{~b}$ & $4.20 \pm 0.43 \mathrm{~b}$ & $3.69 \pm 0.13 \mathrm{~b}$ & $3.25 \pm 0.12 \mathrm{~b}$ \\
\hline \multicolumn{7}{|c|}{ Vegetable treatments } \\
\hline MHD & $35.7 \pm 3.2 \mathrm{c}$ & $32.0 \pm 4.5 \mathrm{~b}$ & $3.75 \pm 0.27 c$ & $3.46 \pm 0.22 b$ & $3.40 \pm 0.17 c$ & $2.82 \pm 0.09$ \\
\hline MIHD & $46.9 \pm 1.6 \mathrm{a}$ & $40.9 \pm 2.2 \mathrm{a}$ & $5.53 \pm 0.36 \mathrm{ab}$ & $4.57 \pm 0.19 \mathrm{a}$ & $3.35 \pm 0.09 c$ & $2.53 \pm 0.15$ \\
\hline MILD & $44.9 \pm 2.5 \mathrm{a}$ & $41.4 \pm 3.5 \mathrm{a}$ & $4.82 \pm 0.49 \mathrm{~b}$ & $4.14 \pm 0.31 \mathrm{ab}$ & $3.24 \pm 0.15 c$ & $2.38 \pm 0.13$ \\
\hline RHD & $49.8 \pm 3.2 \mathrm{a}$ & $38.8 \pm 3.0 \mathrm{ab}$ & $5.92 \pm 0.83 a$ & $4.84 \pm 0.51 \mathrm{a}$ & $5.37 \pm 0.18 \mathrm{a}$ & $3.76 \pm 0.28$ \\
\hline RiHD & $47.9 \pm 2.8 \mathrm{a}$ & $35.2 \pm 2.3 \mathrm{~b}$ & $6.26 \pm 0.61 \mathrm{a}$ & $4.65 \pm 0.12 \mathrm{a}$ & $4.80 \pm 0.10 \mathrm{~b}$ & $3.44 \pm 0.21 \mathrm{k}$ \\
\hline RILD & $41.4 \pm 2.4 \mathrm{~b}$ & $33.3 \pm 3.2 \mathrm{~b}$ & $6.20 \pm 0.27 \mathrm{a}$ & $4.47 \pm 0.11 \mathrm{a}$ & $3.43 \pm 0.08 c$ & $2.37 \pm 0.16$ \\
\hline WxV & Ns & ns & ns & ns & ns & ns \\
\hline
\end{tabular}

MHD: mizuna high density; MIHD: mizuna intercropped high density; MILD: Mizuna intercropped low density; RHD: rocket salad high density; RIHD: rocket salad intercropped high density; RILD: rocket salad low density; HC: hydroponic control; APW: aquaponic water; CAPW: complemented aquaponic water. Different letters on the same DAS indicate significant differences, with $p<0.05$, based on Tukey HSD Test.

Table 5. First growth cycle: Effect of water and vegetable treatments on the ion concentrations.

\begin{tabular}{|c|c|c|c|c|c|c|c|c|c|c|}
\hline & $\mathrm{Cl}^{-}$ & $\mathrm{NO}_{2}{ }^{-}$ & $\mathrm{NO}_{3}^{-}$ & $\mathrm{PO}_{4}{ }^{3-}$ & $\mathrm{SO}_{4}{ }^{2-}$ & $\mathrm{Na}^{+}$ & $\mathrm{NH}_{4}{ }^{+}$ & $\mathrm{K}^{+}$ & $\mathrm{Mg}^{2+}$ & $\mathrm{Ca}^{2+}$ \\
\hline & \multicolumn{10}{|c|}{$\left(\mathrm{mg} \mathrm{kg}^{-1} \mathrm{dw}\right)$} \\
\hline \multicolumn{11}{|c|}{ Nutrient solutions } \\
\hline $\mathrm{HC}$ & 2985 b & $7.24 \mathrm{~b}$ & $4214 b$ & $7664 \mathrm{a}$ & $9539 \mathrm{~b}$ & $1914 b$ & $327 \mathrm{~b}$ & $35,094 \mathrm{a}$ & $6598 \mathrm{~b}$ & $12,136 \mathrm{~b}$ \\
\hline APW & 5473 a & $130 \mathrm{a}$ & 37,753 a & $4808 \mathrm{~b}$ & 31,774 a & 4336 a & 1821 a & $11,999 \mathrm{c}$ & 8010 a & $46,363 \mathrm{a}$ \\
\hline CAPW & $3572 \mathrm{~b}$ & $145 \mathrm{a}$ & $1819 \mathrm{~b}$ & 7998 a & $9468 \mathrm{~b}$ & $1961 \mathrm{~b}$ & $324 \mathrm{~b}$ & $24,719 \mathrm{~b}$ & 4662 c & $12,657 \mathrm{~b}$ \\
\hline \multicolumn{11}{|c|}{ Vegetables treatments } \\
\hline MHD & $4647 \mathrm{a}$ & $40.2 \mathrm{~b}$ & 26,576 a & 6326 & $22,740 \mathrm{a}$ & 3291 a & 896 & 28,039 a & 4982 & 22,044 \\
\hline MIHD & $3402 \mathrm{~b}$ & $30.7 \mathrm{~b}$ & $20,440 \mathrm{ab}$ & 5922 & 20,126 a & $2604 \mathrm{~b}$ & 944 & $23,529 \mathrm{ab}$ & 4945 & 20,908 \\
\hline MILD & $3218 \mathrm{~b}$ & $43.0 \mathrm{~b}$ & $22,008 \mathrm{ab}$ & 4899 & $17,278 \mathrm{ab}$ & $2732 \mathrm{~b}$ & 795 & $20,497 \mathrm{bc}$ & 5108 & 21,949 \\
\hline RHD & $3950 \mathrm{ab}$ & $200 \mathrm{a}$ & $12,704 \mathrm{~b}$ & 4797 & 7232 c & $2503 \mathrm{~b}$ & 846 & $16,649 \mathrm{c}$ & 4850 & 21,911 \\
\hline RIHD & $4536 \mathrm{a}$ & $101 \mathrm{a}$ & 8893 b & 6708 & $10,573 \mathrm{bc}$ & $2517 \mathrm{~b}$ & 697 & $25,132 \mathrm{ab}$ & 5642 & 22,249 \\
\hline RILD & $3987 \mathrm{ab}$ & 207 a & $13,387 \mathrm{~b}$ & 5126 & 9211 c & $2319 b$ & 683 & $20,029 \mathrm{bc}$ & 5558 & 25,638 \\
\hline $\mathrm{WxV}$ & * & ns & * & $*$ & * & * & * & ns & ns & ns \\
\hline
\end{tabular}

MHD: mizuna high density; MIHD: mizuna intercropped high density; MILD: Mizuna intercropped low density; RHD: rocket salad high density; RIHD: rocket salad intercropped high density; RILD: rocket salad low density; HC: hydroponic control; APW: aquaponic water; CAPW: complemented aquaponic water. Different letters on the same DAS indicate significant differences, with $p<0.05$, based on Tukey HSD Test.

Table 6. Second growth cycle: Concentration of ions in the leaf biomass of rocket (R) and mizuna (M) when grown in different nutrient solutions (hydroponic, aquaponic water, complemented aquaponic water) and in different cultivation conditions (densities, intercropping).

\begin{tabular}{|c|c|c|c|c|c|c|c|c|c|c|}
\hline & $\mathrm{Cl}^{-}$ & $\mathrm{NO}_{2}{ }^{-}$ & $\mathrm{NO}_{3}^{-}$ & $\mathrm{PO}_{4}^{3-}$ & $\mathrm{SO}_{4}^{2-}$ & $\mathrm{Na}^{+}$ & $\mathrm{NH}_{4}{ }^{+}$ & $\mathrm{K}^{+}$ & $\mathrm{Mg}^{2+}$ & $\mathrm{Ca}^{2+}$ \\
\hline & \multicolumn{10}{|c|}{$\left(\mathrm{mg} \mathrm{kg}^{-1} \mathrm{dw}\right)$} \\
\hline \multicolumn{11}{|c|}{ Nutrient solutions } \\
\hline $\mathrm{HC}$ & $3185 b$ & $4.98 \mathrm{~b}$ & $4014 \mathrm{~b}$ & 8010 a & $10,053 \mathrm{~b}$ & $2470 \mathrm{~b}$ & $375 \mathrm{~b}$ & $40,086 \mathrm{a}$ & $7272 b$ & $14,152 \mathrm{~b}$ \\
\hline APW & $5637 a$ & $107 \mathrm{a}$ & $34,601 \mathrm{a}$ & 5486 b & $35,070 \mathrm{a}$ & $4674 \mathrm{a}$ & 2391 a & $13,317 \mathrm{c}$ & 8836 a & $51,625 \mathrm{a}$ \\
\hline CAPW & $3666 \mathrm{~b}$ & $119 a$ & $1357 \mathrm{c}$ & 8228 a & 9996 b & $2259 \mathrm{~b}$ & $402 \mathrm{~b}$ & $26,381 \mathrm{~b}$ & $5718 \mathrm{c}$ & $16,511 \mathrm{~b}$ \\
\hline \multicolumn{11}{|c|}{ Vegetables treatments } \\
\hline MHD & $4797 \mathrm{a}$ & $78.2 \mathrm{~b}$ & $21,502 \mathrm{a}$ & $8896 \mathrm{ab}$ & $30,572 \mathrm{a}$ & 4029 a & $1040 \mathrm{a}$ & $33,935 \mathrm{a}$ & 9184 & 29,450 \\
\hline MIHD & $3602 b$ & $38.3 \mathrm{~b}$ & $17,582 \mathrm{~b}$ & $8256 a b$ & 26,978 a & $3102 a b$ & $1270 \mathrm{a}$ & $29,919 \mathrm{ab}$ & 8649 & 29,370 \\
\hline MILD & $3652 \mathrm{~b}$ & $53.0 \mathrm{~b}$ & $14,650 \mathrm{~b}$ & $7893 \mathrm{~b}$ & $22,900 \mathrm{ab}$ & $3314 \mathrm{ab}$ & $1227 \mathrm{a}$ & $26,301 \mathrm{~b}$ & 7900 & 27,693 \\
\hline RHD & $4146 \mathrm{ab}$ & $254 \mathrm{~b}$ & $8778 \mathrm{c}$ & $8103 \mathrm{ab}$ & $13,854 \mathrm{~b}$ & 2993 b & $1132 \mathrm{a}$ & $23,473 \mathrm{~b}$ & 8378 & 27,467 \\
\hline RIHD & $4822 \mathrm{a}$ & $163 \mathrm{a}$ & $6239 c$ & $9554 \mathrm{a}$ & $16,475 \mathrm{~b}$ & $3171 \mathrm{ab}$ & $873 \mathrm{~b}$ & $30,006 \mathrm{ab}$ & 8374 & 28,639 \\
\hline RILD & $4279 \mathrm{ab}$ & $256 \mathrm{a}$ & $8325 c$ & 7908 b & $13,863 \mathrm{~b}$ & $2653 \mathrm{~b}$ & $875 \mathrm{~b}$ & $25,681 \mathrm{~b}$ & 8622 & 29,570 \\
\hline $\mathrm{WxV}$ & * & ns & $*$ & $*$ & * & $*$ & $*$ & ns & ns & ns \\
\hline
\end{tabular}

MHD: mizuna high density; MIHD: mizuna intercropped high density; MILD: Mizuna intercropped low density; RHD: rocket salad high density; RIHD: rocket salad intercropped high density; RILD: rocket salad low density; HC: hydroponic control; APW: aquaponic water; CAPW: complemented aquaponic water. Different letters on the same DAS indicate significant differences, with $p<0.05$, based on a Tukey HSD Test. 


\section{Discussion}

\subsection{Water Quality}

Water quality significantly influenced the vegetable yield in both crop cycles. The higher water consumption in the HC and CAPW treatments can be related to better plant development in comparison to the plants in the APW treatment. Better growth was linked to the greater leaf surface area, and thus to an increase in evapotranspiration [4]. Better plant development was due to the availability and balance of nutrients that strongly influenced the entire crop cycle. Unbalanced nutrients in the APW treatment negatively influenced the uptake of other nutrient as described in Bindraban et al. [23] who reported that antagonism among nutrient elements often occurs when the ratios of elements are unbalanced. In both crop cycles, each nutrient was characterized by the same specific pattern (i.e., $\mathrm{NO}_{3}-\mathrm{N}, \mathrm{NH}_{4}-\mathrm{N}, \mathrm{P}, \mathrm{K}$ ) although their absolute water concentration was different between growth cycles. As a consequence, each nutrient pattern can provide useful information that can be transferred from one crop cycle to another one. The $\mathrm{N}^{-\mathrm{NO}_{3}}$ concentration in the nutrient solution was suitable for the cultivation of the studied species. The $\mathrm{N}_{-} \mathrm{NO}_{3}$ requirement was low in the first two weeks and then increased exponentially during the middle and final parts of the cycle, with the greatest absorption seen in the plants grown in the CAPW treatment. The exponential increase in nutrient uptake during the crop cycle confirm what has already been reported by Silberbush and Ben-Asher [24], whereas new interesting perspectives can be derived from the higher nutrient absorption capacity exhibited by the plants grown in the CAPW treatment. The latter result reveals a possible biostimulant power of aquaponic effluents. Although the aim of this study was not to ascertain which mechanism or compound exerts the type of biostimulant effect described by Delaide et al. [25], we can speculate that certain microorganisms and dissolved organic matter (DOM) could play important roles. Taking into account the experimental conditions (cultivation was not within the AP system, but separate) we can postulate that the effect of DOM might have been greater than the effect of microorganisms. This is supported by Canellas et al. [26], who reported that humic and fulvic acids have an effect on plant primary and secondary metabolism, and humic substances in particular enhance root growth, nutrient uptake, and crop tolerance to environmental stresses. The presence of $\mathrm{N}-\mathrm{NH}_{4}$ in the water derived from the AP system was very low, showing the system performed well when nitrogen was transformed by biological nitrification and denitrification, and was assimilated by plants in the form of nitrate $\left(\mathrm{NO}_{3}{ }^{-}\right)$and ammonium $\left(\mathrm{NH}_{4}{ }^{+}\right)[5,27]$. The P content of the water in the APW system was not enough for vegetable production in soilless systems. This result was also obtained in other experiments and shows the need for nutrient supplementation (especially $\mathrm{P}$ and $\mathrm{K}$ ) in order to meet the main nutritional needs of the crops [28-31]. The addition of $\mathrm{K}$ and $\mathrm{P}$ can be considered an indispensable condition for obtaining suitable production levels. This sentence is also confirmed by recent aquaponic studies which state that the majority $(>50 \%)$ of nutrients that sustain the optimal plant growth are derived from waste originating from feeding aquatic organisms [13]. As a matter of fact, the AP water is generally unbalanced in favor of the nitrogenous compounds, causing unbalanced conditions for the plant. This requirement, already marked for leafy species, is even more stringent for fruit vegetables, as tomatoes require high quantities of $\mathrm{P}$ and $\mathrm{K}$ to complete fruit production and development. Higher fluctuations in the $\mathrm{S}, \mathrm{Ca}$, and $\mathrm{Mg}$ levels were observed in biomass from the 2nd cycle compared to the 1st one. This result could be due to the different climatic conditions experienced by the plants during the 2nd growth cycle (more irradiance and higher air temperatures) that can greatly affect the nutrient uptake of the crop. This is in agreement with the findings reported in soilless culture by Urrestarazu et al. [32] in two cucurbit crops and by Amalfitano et al. [33] in "Friariello" pepper.

\subsection{Vegetable Species}

The cultivated species have different production potentials in relation to both the cultivation system and the type of water used. Mizuna was most suitable for the cultivation offered conditions. The rusticity of this model species has also been highlighted in other studies [34]. Mizuna had a much 
higher yield than rocket salad, which is mainly linked to the greater capacity of $\mathrm{M}$ to develop a strong root system that is able to expand throughout the cultivation carpet. R never reached the root growth levels of M, perhaps revealing some limitations in NFT cultivation, despite having already been used in other studies [9]. From a production point of view, the response patterns of the different treatments did not differ between the cultivation cycles. However, there was a significant difference in absolute yield values, which were higher in the second cycle, mainly due to the more suitable climatic conditions (irradiance and temperature). The yield data recorded for M in the HC and CAPW systems were lower than those recorded by D'Imperio et al. [35], who identified production yields close to $4.2 \mathrm{~kg} \mathrm{~m}^{-2}$. The $\mathrm{R}$ productivity was very poor and $75 \%$ lower than that produced in other studies [36,37]. In terms of the interaction between the vegetable treatments and the nutrient solutions, both cultivation cycles in the HC and CAPW systems produced substantially similar yields with an increase in favor of CAPW. This result is probably linked to the biostimulant activity of the organic fraction released by the fish into the water [25]. This result is also confirmed by the chlorophyll content (SPAD values) readings that clearly highlight the best nutritional conditions in the HC and CAPW systems, whose values were in line with those verified by Colonna et al. [19] for the same species cultivated in optimal conditions. It is interesting to note that in both cultivation cycles, the chlorophyll content was higher in the CAPW system than in the HC system. This result confirms the previously highlighted fact about the greater absorption capacity of the CAPW plants.

The cultivation method and the water type used also significantly affected the quality of the crops. Significant increases in total antioxidant capacity and total polyphenols were observed from the HC and APW systems. This result can be justified by the more stressful conditions that the plants were exposed to during the crop cycle in the APW system. A possible stressful situation that might have arisen in the APW system in particular might be connected to the unbalanced presence of nutrients that could not guarantee an adequate nutrient supply to the plants [28-31]. The lower values of antioxidants and total phenols found in the CAPW could be traced to better nutritional values in the crop, which is also confirmed by other production (marketable biomass) and nutritional (chlorophyll content) parameters. The antioxidant values measured in both species are in agreement with the findings of Martínez-Sánchez et al. [38], who did not see significant differences between rocket and mizuna. In terms of the concentration of vitamin C, there were significant differences, especially in the plants grown in the APW system; this further demonstrates the stressful conditions experienced by the plants. The species intercropping (especially for $\mathrm{M}$ ) clearly highlighted a significant increase in antioxidant compounds. This result is linked to the greater competition between the plants and to the probable effects of radical allelopathy between the two crops. Similar results have also been found for other intercropped vegetables (e.g., red chicory lettuce) grown in aquaponics systems, as reported by Maucieri et al. [39]. The intercropping also had significant effects on vitamin $C$ concentrations of R. Species intercropping in particular led to a decrease in the vitamin C content, as described by other studies carried out with other species (tomato-garlic) in soil cultivation systems [40]. Finally, in terms of the mineral compound content in the plants, the APW treatment resulted in significantly higher concentrations of $\mathrm{Cl}^{-}, \mathrm{NO}_{2}{ }^{-}, \mathrm{NO}_{3}{ }^{-}, \mathrm{SO}_{4}{ }^{2-}, \mathrm{Na}^{+}, \mathrm{NH}_{4}{ }^{+}, \mathrm{Mg}^{2+}$, and $\mathrm{Ca}^{2+}$ compared to those concentrations in the HC and CAPW systems. These results were observed in both crop cycles, demonstrating the nutritional imbalance present in the APW. The remarkable $\mathrm{NO}_{3}{ }^{-}$content in the APW system plants was evident; on average, $88.8 \%$ and $95.2 \%$ higher than the plants from the HC and CAPW systems, respectively. This result can be justified by the reduced presence of other macronutrients [28-31]. The $\mathrm{NO}_{3}{ }^{-}$values were on average higher in $\mathrm{M}$, however, the values did not exceed the limits set by European Regulation no. 1258/2011 for certain leafy vegetables (lettuce, spinach, and rocket salad). Although the results from the different crop cycles were similar, a general reduction in the $\mathrm{NO}_{3}{ }^{-}$content was observed in the second crop cycle. This outcome is linked to variations in environmental conditions in terms of light intensity. On average, April is characterized by higher light intensity than March, which influenced the nitrate-reductase enzyme activity, reducing the $\mathrm{NO}_{3}{ }^{-}$content, as shown in several studies [41-44]. This result is backed up by the results from 
a study investigating Lactuca sativa (L.) var. acephala cultivated in a floating system [45]. The same authors reported that in the presence of low soluble nutrient concentrations ( 2 mequiv. $\left.\mathrm{L}^{-1}\right)$ and low electrical conductivity $\left(0.3 \mathrm{dS} \mathrm{m}^{-1}\right)$, the $\mathrm{NO}_{3}{ }^{-}$content in the summer cycle was lower than in spring. However, this effect was not observed for higher soluble nutrient concentrations. It is also possible that high Ca absorption by plants cultivated in APW contributed to a reduction in potassium uptake due to the well-known antagonistic effect between the two elements [46].

\section{Conclusions}

The experimental evidence recorded during this experience highlighted the fact that the low production potential of APW is heavily influenced by the substantial absence of P and K. Supplementing water with these elements made it possible to obtain results that were comparable to the hydroponic control. In the case of mizuna, the yield values obtained in CAPW were significantly higher than those from the HC, probably due to biostimulant effects connected to the presence of organic and microbial components from fish farming. In terms of crop choice, mizuna delivered better productive results than did the rocket salad, adapting well to the NFT cultivation system. From a qualitative point of view, the water type, cultivation density, and intercropping significantly influenced the qualitative characteristics for both antioxidant compounds and mineral profile. Therefore, it is possible to state that the extension of aquaponic water utilization for NFT of baby-leaf production is a viable method if the missing nutrients are supplemented; moreover, this method improves the water use and the nitrogen use efficiency of fish farming, further limiting its environmental impact.

Author Contributions: C.N. C.M., and R.J. conceived and designed the experiments; C.N. and Z.S. performed the experiments; C.N. and C.M. analyzed the data; R.J. and P.S. contributed reagents/materials/analysis tools; C.N., C.M., Z.S., T.K., A.M., and R.J. wrote the paper.

Acknowledgments: This research was supported by COST Action FA1305 "The EU Aquaponics Hub; Realising Sustainable Integrated Fish and Vegetable Production for the EU". Carlo Nicoletto's work was supported by a COST-STSM-ECOST-STSM-FA1305-011016-080268 grant and by the Department of Agronomy, Food, Natural resources, Animals and Environment (DAFNAE)_University of Padova. We thank Darren Mace for language corrections.

Conflicts of Interest: The authors declare no conflict of interest.

\section{References}

1. Godfray, H.C.J.; Beddington, J.R.; Crute, I.R.; Haddad, L.; Lawrence, D.; Muir, J.F.; Pretty, J.; Robinson, S.; Thomas, S.M.; Toulmin, C. Food security: The challenge of feeding 9 billion people. Science 2010, 327, 812-818. [CrossRef] [PubMed]

2. Rakocy, J.; Shultz, R.C.; Bailey, D.S.; Thoman, E.S. Aquaponic production of tilapia and basil: Comparing a batch and staggered cropping system. In Proceedings of the South Pacific Soilless Culture Conference (SPSCC), Palmerston North, New Zealand, 10-13 February 2003; Volume 648, pp. 63-69.

3. Junge, R.; König, B.; Villarroel, M.; Komives, T.; Jijakli, M.H. Strategic Points in Aquaponics. Water 2017, 9 , 182. [CrossRef]

4. Maucieri, C.; Nicoletto, C.; Junge, R.; Schmautz, Z.; Sambo, P.; Borin, M. Hydroponic system sand water management in aquaponics: A review. Ital. J. Agron. 2018, 13, 1-11.

5. Graber, A.; Junge, R. Aquaponic Systems: Nutrient recycling from fish wastewater by vegetable production. Desalination 2009, 246, 147-156. [CrossRef]

6. Shete, A.P.; Verma, A.K.; Chadha, N.K.; Prakash, C.; Peter, R.M.; Ahmad, I.; Nuwansi, K.K.T. Optimization of hydraulic loading rate in aquaponic system with Common carp (Cyprinus carpio) and Mint (Mentha arvensis). Aquacult. Eng. 2016, 72, 53-57. [CrossRef]

7. Espinosa Moya, E.A.; Angel Sahagún, C.A.; Mendoza Carrillo, J.M.; Albertos Alpuche, P.J.; Álvarez-González, C.A.; Martínez-Yáñez, R. Herbaceous plants as part of biological filter for aquaponics system. Aquacult. Res. 2016, 47, 1716-1726. [CrossRef]

8. Diver, S. Aquaponics-Integration of Hydroponics with Aquaculture; Attra: Melbourne, Australia, 2000.

9. Lennard, W. A New Look at NFT Aquaponics. Aquapon. J. 2010, 56, 4. 
10. Goddek, S.; Espinal, C.A.; Delaide, B.; Jijakli, M.H.; Schmautz, Z.; Wuertz, S.; Keesman, K.J. Navigating towards decoupled aquaponic systems: A system dynamics design approach. Water 2016, 8, 303. [CrossRef]

11. Al-Hafedh, Y.S.; Alam, A.; Beltagi, M.S. Food production and water conservation in a recirculating aquaponic system in Saudi Arabia at different ratios of fish feed to plants. J. World Aquacult. Soc. 2008, 39, 510-520. [CrossRef]

12. Bittsanszky, A.; Uzinger, N.; Gyulai, G.; Mathis, A.; Junge, R.; Kotzen, B.; Komives, T. Nutrient supply of plants in aquaponic systems. Ecocycles 2016, 2,17-20. [CrossRef]

13. Palm, H.W.; Knaus, U.; Appelbaum, S.; Goddek, S.; Strauch, S.M.; Vermeulen, T.; Kotzen, B. Towards commercial aquaponics: A review of systems, designs, scales and nomenclature. Aquacult. Int. 2018, 1, 30. [CrossRef]

14. Goddek, S.; Keesman, K.J. The necessity of desalination technology for designing and sizing multi-loop aquaponics systems. Desalination 2018, 428, 76-85. [CrossRef]

15. Kyriacou, M.C.; Rouphael, Y.; Di Gioia, F.; Kyratzis, A.; Serio, F.; Renna, M.; Santamaria, P. Micro-scale vegetable production and the rise of microgreens. Trends Food Sci. Technol. 2016, 57, 103-115. [CrossRef]

16. Gonnella, M.; Serio, F.; Conversa, G.; Santamaria, P. Yield and quality of lettuce grown in floating system using different sowing density and plant spatial arrangements. In Proceedings of the VI International Symposium on Protected Cultivation in Mild Winter Climate: Product and Process Innovation, 5-8 March 2002; Volume 614, pp. 687-692.

17. Subhasree, B.; Baskar, R.; Keerthana, R.L.; Susan, R.L.; Rajasekaran, P. Evaluation of antioxidant potential in selected green leafy vegetables. Food Chem. 2009, 115, 1213-1220. [CrossRef]

18. Saini, R.K.; Ko, E.Y.; Keum, Y.S. Minimally processed ready-to-eat baby-leaf vegetables: Production, processing, storage, microbial safety, and nutritional potential. Food Rev. Int. 2017, 33, 644-663. [CrossRef]

19. Colonna, E.; Rouphael, Y.; Barbieri, G.; De Pascale, S. Nutritional quality of ten leafy vegetables harvested at two light intensities. Food Chem. 2016, 199, 702-710. [CrossRef] [PubMed]

20. Fernandez, D. HydroBuddy: An Open Source Nutrient Calculator for Hydroponics and 464 General Agriculture, v1.5. 2013. Available online: http:/ / scienceinhydroponics.com (accessed on 15 February 2017).

21. Singleton, V.L.; Orthofer, R.; Lamuela-Raventós, R.M. Analysis of total phenols and other oxidation substrates and antioxidants by means of folin-ciocalteu reagent. Methods Enzymol. 1999, 299, 152-178. [CrossRef]

22. Benzie, I.F.; Strain, J.J. The ferric reducing ability of plasma (FRAP) as a measure of "antioxidant power": The FRAP assay. Anal. Biochem. 1996, 239, 70-76. [CrossRef] [PubMed]

23. Bindraban, P.S.; Dimkpa, C.; Nagarajan, L.; Roy, A.; Rabbinge, R. Revisiting fertilisers and fertilisation strategies for improved nutrient uptake by plants. Biol. Fert. Soils 2015, 51, 897-911. [CrossRef]

24. Silberbush, M.; Ben-Asher, J. Simulation study of nutrient uptake by plants from soilless cultures as affected by salinity buildup and transpiration. Plant Soil 2001, 233, 59-69. [CrossRef]

25. Delaide, B.; Goddek, S.; Gott, J.; Soyeurt, H.; Jijakli, M.H. Lettuce (Lactuca sativa L. Var. Sucrine) growth performance in complemented aquaponic solution outperforms hydroponics. Water 2016, 8, 467. [CrossRef]

26. Canellas, L.P.; Olivares, F.L.; Aguiar, N.O.; Jones, D.L.; Nebbioso, A.; Mazzei, P.; Piccolo, A. Humic and fulvic acids as biostimulants in horticulture. Sci. Hortic. 2015, 196, 15-27. [CrossRef]

27. Wongkiew, S.; Hu, Z.; Chandran, K.; Lee, J.W.; Khanal, S.K. Nitrogen transformations in aquaponic systems: A review. Aquacult. Eng. 2017, 76, 9-19. [CrossRef]

28. Cerozi, B.S.; Fitzsimmons, K. Phosphorus dynamics modeling and mass balance in an aquaponics system. Agric. Syst. 2017, 153, 94-100. [CrossRef]

29. Roosta, H.R.; Hamidpour, M. Effects of foliar application of some macro-and micro-nutrients on tomato plants in aquaponic and hydroponic systems. Sci. Hortic. 2011, 129, 396-402. [CrossRef]

30. Roosta, H.R. Effects of foliar spray of $\mathrm{K}$ on mint, radish, parsley and coriander plants in aquaponic system. J. Plant Nutr. 2014, 37, 2236-2254. [CrossRef]

31. Pineda-Pineda, J.; Miranda-Velázquez, I.; Rodríguez-Pérez, J.E.; Ramírez-Arias, J.A.; Pérez-Gómez, E.A.; García-Antonio, I.N.; Morales-Parada, J.J. Nutrimental balance in aquaponic lettuce production. Acta Hortic. 2017, 1170, 1093-1100. [CrossRef]

32. Urrestarazu, M.; del Carmen Salas, M.; Valera, D.; Gómez, A.; Mazuela, P.C. Effects of heating nutrient solution on water and mineral uptake and early yield of two cucurbits under soilless culture. J. Plant Nutr. 2008, 31, 527-538. [CrossRef] 
33. Amalfitano, C.; Del Vacchio, L.; Somma, S.; Cuciniello, A.; Caruso, G. Effects of cultural cycle and nutrient solution electrical conductivity on plant growth, yield and fruit quality of "Friariello" pepper grown in hydroponics. Hort. Sci. 2017, 44, 91-98. [CrossRef]

34. Bergstrand, K.J.; Hultin, S. Development of strategies for hydroponic cultivation in vertical systems. Acta Hortic. 2014, 1034, 149-156. [CrossRef]

35. D’Imperio, M.; Renna, M.; Cardinali, A.; Buttaro, D.; Serio, F.; Santamaria, P. Calcium biofortification and bioaccessibility in soilless "baby leaf" vegetable production. Food Chem. 2016, 213, 149-156. [CrossRef] [PubMed]

36. Santamaria, P.; Elia, A.; Serio, F. Effect of solution nitrogen concentration on yield, leaf element content, and water and nitrogen use efficiency of three hydroponically-grown rocket salad genotypes. J. Plant Nutr. 2002, 25, 245-258. [CrossRef]

37. Tuncay, Ö.; Eşiyok, D.; Yağmur, B.; Okur, B. The effect of nitrogen sources on yield and quality of salad rocket grown in different months of the year. J. Plant Nutr. 2011, 34, 477-491. [CrossRef]

38. Martínez-Sánchez, A.; Gil-Izquierdo, A.; Gil, M.I.; Ferreres, F. A comparative study of flavonoid compounds, vitamin C, and antioxidant properties of baby leaf Brassicaceae species. J. Agric. Food Chem. 2008, 56, 2330-2340. [CrossRef] [PubMed]

39. Maucieri, C.; Nicoletto, C.; Schmautz, Z.; Sambo, P.; Komives, T.; Borin, M.; Junge, R. Vegetable Intercropping in a Small-Scale Aquaponic System. Agronomy 2017, 7, 63. [CrossRef]

40. Liu, T.; Cheng, Z.; Meng, H.; Ahmad, I.; Zhao, H. Growth, yield and quality of spring tomato and physicochemical properties of medium in a tomato/garlic intercropping system under plastic tunnel organic medium cultivation. Sci. Hortic. 2014, 170, 159-168. [CrossRef]

41. Santamaria, P.; Elia, A.; Gonnella, M. Changes in nitrate accumulation and growth of endive plants during the light period as affected by nitrogen level and form. J. Plant Nutr. 1997, 20, 1255-1266. [CrossRef]

42. Santamaria, P.; Gonnella, M.; Elia, A.; Parente, A.; Serio, F. Ways of reducing rocket salad nitrate content. Acta Hort. 2001, 548, 529-536. [CrossRef]

43. Santamaria, P. Nitrate in vegetables: Toxicity, content, intake and EC regulation. J. Sci. Food Agric. 2006, 86, 10-17. [CrossRef]

44. Caruso, G.; Conti, S.; La Rocca, G. Influence of crop cycle and nitrogen fertilizer form on yield and nitrate content in different species of vegetables. Adv. Hort. Sci. 2011, 25, 81-89.

45. Fallovo, C.; Rouphael, Y.; Rea, E.; Battistelli, A.; Colla, G. Nutrient solution concentration and growing season affect yield and quality of Lactuca sativa L. var. acephala in floating raft culture. J. Sci. Food Agric. 2009, 89, 1682-1689. [CrossRef]

46. Jakobsen, S.T. Interaction between plant nutrients: III. Antagonism between potassium, magnesium and calcium. Acta Agric. Scand. B Soil Plant Sci. 1993, 43, 1-5. [CrossRef] 